NBER WORKING PAPER SERIES

\title{
STREAMING REACHES FLOOD STAGE: DOES SPOTIFY STIMULATE OR DEPRESS MUSIC SALES?
}

\author{
Luis Aguiar \\ Joel Waldfogel \\ Working Paper 21653 \\ http://www.nber.org/papers/w21653
NATIONAL BUREAU OF ECONOMIC RESEARCH
1050 Massachusetts Avenue
Cambridge, MA 02138
October 2015

Thanks to seminar participants at IPTS, the SEEK Digital Economy Workshop at the Collegio Carlo Alberto in Turin, and Zurich/ETH. Joel Waldfogel has served as a consultant to Pandora. The views expressed in the paper are those of the authors' and should not in any circumstances be regarded as stating an official position of the European Commission, the EC Joint Research Center, the IPTS, or the National Bureau of Economic Research.

At least one co-author has disclosed a financial relationship of potential relevance for this research. Further information is available online at http://www.nber.org/papers/w21653.ack

NBER working papers are circulated for discussion and comment purposes. They have not been peerreviewed or been subject to the review by the NBER Board of Directors that accompanies official NBER publications.

(C) 2015 by Luis Aguiar and Joel Waldfogel. All rights reserved. Short sections of text, not to exceed two paragraphs, may be quoted without explicit permission provided that full credit, including $\odot$ notice, is given to the source. 
Streaming Reaches Flood Stage: Does Spotify Stimulate or Depress Music Sales?

Luis Aguiar and Joel Waldfogel

NBER Working Paper No. 21653

October 2015

JEL No. L11,L82

\begin{abstract}
$\underline{\text { ABSTRACT }}$
Streaming music services have exploded in popularity in the past few years, variously raising optimism and concern about their impacts on recorded music revenue. On the one hand, streaming services allow sellers to engage in bundling with the promise of increasing revenues, profits, and consumer surplus. Successful bundling would indeed translate some of the interest in music not generating revenue through individual track sales - unpaid consumption and deadweight loss - into willingness to pay for the bundled offering. On the other hand, streaming may displace traditional individual track sales. Even if they displace sales, streams may however still raise overall revenue if the streaming payment is large enough in relation to the extent of sales displacement. We make use of the growth in Spotify use during the years 2013-2015 to measure its impact on unpaid consumption and on the sales of recorded music. We find that Spotify use displaces permanent downloads. In particular, 137 Spotify streams appear to reduce track sales by 1 unit. Consistent with the existing literature, our analysis also shows that Spotify displaces music piracy. Given the current industry's revenue from track sales ( $\$ 0.82$ per sale) and the average payment received per stream ( $\$ 0.007$ per stream), our sales displacement estimates show that the losses from displaced sales are roughly outweighed by the gains in streaming revenue. In other words, our analysis shows that interactive streaming appears to be revenue-neutral for the recorded music industry.
\end{abstract}

Luis Aguiar

IPTS - Edificio Expo

calle Inca Garcilaso 3

41092 Sevilla (Spain)

luis.aguiar@ec.europa.eu

Joel Waldfogel

Frederick R. Kappel Chair in Applied Economics

3-177 Carlson School of Management

University of Minnesota

321 19th Avenue South

Minneapolis, MN 55455

and NBER

jwaldfog@umn.edu 


\section{Introduction}

Interactive streaming music distribution is growing rapidly around the world, raising questions about its impact on the revenue to rights holders generated by recorded music. Since 2010, the number of active Spotify users has grown from 15 to 60 million worldwide. While some observers hail streaming as the salvation of a recorded music industry dogged by piracy, others raise alarm about low payments from streaming services and displacement of permanent downloads. Musician disclosures of royalty statements from streaming services led the New York Times to question "whether these micropayments can add up to anything substantial." 1

Anecdotes aside, economics offers two broad ways to think about streaming. First, streaming offerings are bundles of zero-marginal cost products. Given that different consumers' valuations of songs are not perfectly positively correlated, streaming bundles hold the possibility of raising revenue, consumer surplus, or possibly both, depending on how they are priced. ${ }^{2}$ Successful bundling would translate some of the interest in music not generating a la carte sales - unpaid consumption and deadweight loss - into willingness to pay for the bundled offering. ${ }^{3}$

Understanding whether streaming stimulates or displaces the sales of recorded music is vital to our understanding of its impact on the fortunes of the recorded music industry. Some argue that streaming functions as music promotion, much like traditional terrestrial radio. If this is true, then this demand stimulation - combined with greater appropriability made possible by bundling - would give streaming an unambiguously positive impact on recorded music revenue. Others believe that streaming functions as a substitute for the permanent downloads of digital music, muting the benefits. But even if streaming displaces sales, it does not necessarily depress music revenue; that depends on whether the streaming payment is high enough to offset and potentially overcome the reduction in revenue from forgone permanent downloads. Digital revenue is the sum of revenue from permanent downloads and streams. That is, rev $=p_{d} q_{d}+p_{s} S$, where $q_{d}$ is the number of paid digital downloads, $S$ is the number of streams, and $p_{d}$ and $p_{s}$ are the revenues

\footnotetext{
${ }^{1}$ Sisario, Ben. "As Music Streaming Grows, Royalties Slow to a Trickle." New York Times, Jan. 28, 2013. http://www.nytimes. com/2013/01/29/business/media/streaming-shakes-up-music-industrys-model -for-royalties.html. The article describes the payments to cellist Zoe Keating. Musician David Lowery complained that Pandora paid him $\$ 16.89$ for playing his famous song "Low" a million times, "less than what [he] make[s] from a single t-shirt sale!" See Hogan (2013) (http://www.spin.com/articles/pandora-davidlowery-cracker-low-royalties-debate-streaming/?fullsite=true). Finally, Radiohead's Thom Yorke has colorfully called Spotify "the last desperate fart of a dying corpse." (http://www.theguardian.com/technolog y/2013/oct/07/spotify-thom-yorke-dying-corpse).

${ }^{2}$ See the literature on bundling in general (Stigler, 2007; Adams and Yellen, 1976; Schmalensee, 1984) and music bundling in particular (Shiller and Waldfogel, 2011).

${ }^{3}$ Streaming also represents a business strategy of renting, as opposed to selling, access to recorded music, which can be advantageous for producers by eliminating resale, among other mechanisms (Varian, 2000).
} 
generated per digital download and stream, respectively. If downloads depend on streams, then $q_{d}=q_{d}(S)$, and the change in revenue with an additional stream is $\frac{\partial r e v}{\partial S}=p_{d} \frac{\partial q_{d}}{\partial S}+p_{s}$. An increase in streaming therefore raises revenue if a negative impact of streaming on sales is sufficiently small, i.e. if $\frac{\partial q_{d}}{\partial S}>-\frac{p_{s}}{p_{d}}$.

Hence, it is of substantial interest to know not only whether streaming displaces sales but, if so, at what rate. In addition, we need to compare the rate of sales displacement with the relative payments to rights holders for streaming and a la carte permanent sales in order to determine whether streaming raises or reduces recorded music industry revenue.

The goal of this paper is to analyze data on streaming, sales, and unpaid consumption to determine how streaming is affecting revenue to the recorded music industry. The first - and main - empirical task is to measure the impact of streaming on sales, as well as the impact of streaming on piracy. To measure the impact of these services on these consumption outcomes, we might ideally launch services in some countries and not others, then monitor what happens to sales and unpaid downloads. Recent experience bears some resemblance to this experimental ideal. Spotify, founded in 2006, has grown at different rates in different countries and has grown very quickly since 2011. While its entry and growth is not literally an experiment, the growth is sufficiently abrupt that examining the co-movement of streaming and recorded music sales holds the promise of revealing the potential impact of streaming on sales.

Beyond the obvious challenges of finding exogenous variation in the volume of streaming, there is the more mundane challenge of simply obtaining data on the volumes of music sales, streaming, and piracy. Data on the volume of streams has until recently been entirely unavailable. Beginning in April 2013, however, Spotify began releasing the number of weekly streams for the top 50 songs, by country. ${ }^{4}$ Thus, by aggregating the streams of the top 50 songs by country and week, we have a country-specific index of Spotify use for roughly two years (April 2013-March 2015). Data on the volumes of sales and piracy are also hard to find, but we have obtained weekly data on song-level digital sales in each of 21 countries, 2012-2013, along with the weekly levels of piracy via torrents for 8,000 artists over the same period. Hence, we can ask how music sales and piracy evolve with the growth of Spotify during a period of fairly substantial growth in this interactive streaming channel. Because we have song-level sales data and artist-level piracy data, we can merge these with our Spotify streaming dataset. We can therefore attempt to measure sales and piracy displacement at the micro and aggregate levels for a particular subset of songs and artists. Finally, for one of the countries - the US - we have music sales data

\footnotetext{
${ }^{4}$ In October, 2014 they extended this list to the top 200 songs.
} 
for 2012-early 2015, covering a period of more substantial growth in Spotify use.

This paper proceeds in five sections after the introduction. Section 2 provides background on two issues related to streaming, sales displacement and bundling, as well as evidence on the recent growth in interactive streaming that we can use to document its impact. Section 3 turns to our data sources. Section 4 describes our various identification strategies for measuring the effects of streaming on sales and unpaid consumption, given the data at hand. Section 5 presents our results. Song-level regressions of sales on streaming yield consistently positive coefficients, consistent with either song-level sales stimulation or unobserved heterogeneity. Artist-level regressions of unpaid consumption on streaming also yield positive coefficients, again consistent with either artist-level piracy stimulation or unobserved heterogeneity. Aggregate-level regressions, which treat the growth in Spotify as exogenous to the demand for music, yield consistently negative coefficients, for both the impacts of streaming on sales and piracy. Our preferred estimate indicates that an additional 137 streams displaces one track sale, while an additional 47 streams displaces one unpaid download. Section 6 uses our estimates of the revenue associated with track sales and streams to calculate that the recent growth in streaming appears roughly revenue-neutral for the recorded music industry. Section 7 concludes.

\section{Background}

\subsection{Streaming, Airplay, and Effects on Sales}

There are two distinct types of streaming music services, interactive and non-interactive. The interactive services, such as Spotify, YouTube, and Deezer, allow users to choose which song they will hear. Of Spotify's 60 million users, one quarter pay $\$ 10$ per month for the service. The others pay nothing but generate "pay" indirectly through their exposure to advertising. Non-interactive services such as Pandora do not allow users to choose the particular songs they hear, but Pandora does allow users to create narrowly tailored stations (consisting of songs similar to a seed song or artist).

Streaming services tend to describe themselves as tools for musical discovery. For example, Pandora has a "mission to reward the musically curious among us with a never-ending experience of music discovery." 5 Similarly, "Spotify makes it easier than ever to discover, manage and share

\footnotetext{
${ }^{5}$ https://www. pandora.com/about.
} 
music with your friends, while making sure that artists get a fair deal." ${ }^{6}$ Under this conception of streaming services, they resemble terrestrial radio stations, which are widely believed to stimulate sales of recorded music. The basis for this belief is the observation that the particular songs on the radio tend to sell more when they are being aired. Moreover, and related, songs on the radio tend to sell better than those not receiving airplay. ${ }^{7}$

If streaming resembles traditional radio airplay and stimulates demand for recorded music, for example through permanent digital downloads, then the recent growth in streaming should raise revenue, all else constant. Even if the analogy to traditional radio is accurate, it is important to note that understanding the impact of airplay on sales is challenging, for both empirical and theoretical reasons. First, documenting the impact is empirically challenging: radio airplay of a song is endogenous, and songs are aired on radio mostly upon release, when consumers are interested in purchasing the recently-released titles for other reasons.

Liebowitz (2004) articulates a second important challenge, a possible "fallacy of compostition." Even if the radio airplay of particular songs stimulates their sales, the airplay of songs generally need not stimulate overall sales of recorded music. The relevant experiment for measuring the overall impact is growth in the use of the medium, not change in the airplay of particular songs. Liebowitz (2004) studies the period surrounding the diffusion of radio broadcasting and its effect on the already-established recorded music industry in the US during the 1920s. He documents that the diffusion of radio was accompanied by a collapse of the recorded music industry, which he interprets as displacement of recorded music sales by radio.

This interpretation of the experience of the 1920s is intriguing, but it is also true that the experience of the US radio and recorded music industries over the subsequent 50 years suggests a rather different relationship between radio broadcasting and recorded music sales. As Figure 1 shows, while per capita record sales decreased with radio diffusion during the 1920s, both grew between 1930 and 1980, raising questions about whether radio airplay displaces sales.

The impact of airplay on recorded music sales has acquired new importance with the recent growth in Internet radio, or streaming. Unlike traditional radio, which exposes people to a broad selection of generally unfamiliar music, streaming services tend to provide very narrow selections of music. The largest non-interactive service, Pandora, allows consumers to seed their own stations with a song or an artist they like. The station then plays songs and artists similar

\footnotetext{
${ }^{6}$ https://press.spotify.com/us/2013/05/29/hello-music-discovery-spotify-here/.

${ }^{7}$ See Dertouzos (2004), a study undertaken for the National Association of Broadcasters, which found a positive effect of radio airplay on overall music sales.
} 
to the seed, according to various criteria, including musicological similarity and evidence about which music is liked in common among consumers. To the extent that Internet radio serves consumers what they want to hear, it may obviate additional purchases (beyond the possible purchase of access to Internet radio). In that case, streaming would serve as a substitute rather than a complement for recorded music purchases.

Spotify takes selection a step further than Pandora. Users choose exactly which songs they will hear. Premium (paid) users can entirely control what they hear on both fixed and mobile devices. Free users also have full control over what they want to listen to on their fixed devices, but they have less control on their mobile devices, where they can only shuffle among and/or within playlists. Whether Internet radio stimulates or depresses recorded music sales is an open question. The control that users have over what they hear at least raises the possibility that Internet radio would exert a less stimulating impact on sales than terrestrial radio.

Some recent research examines the impact of streaming on recorded music sales. First, Hiller and Kim (2014) study the impact of video availability on YouTube on sales of corresponding albums. Music released by Warner was unavailable on YouTube during a contract dispute. During this period, the excluded music experienced better (higher sales) ranks on the Billboard 200 weekly album ranking, relative to albums from other labels. This evidence indicates that the streaming available at YouTube cannibalizes sales of albums. Second, Kretschmer and Peukert (2014) undertake a similar exercise, studying the impact of videos excluded from YouTube in Germany. They find that availability of an artist's video on YouTube stimulates sales of the artist's albums but not the individual song. Third, data scientists at Pandora have undertaken A/B experiments, turning off songs in random geographic areas, then asking whether sales of those songs are higher or lower in places where the songs continue to play. McBride (2014) finds that song sales are 2 percent lower in DMAs where the songs are not played. It is worth noting, however, that these are all song-level studies, which are therefore potentially vulnerable to Leibowitz's concern about a fallacy of composition that a relationship holding for individual works may not hold for music as a whole.

Finally, while there is no corresponding study of Spotify, founder Daniel Ek has publicly argued that it is a "myth" that "Spotify hurts sales, both download and physical. This is classic correlation without causation." 8 Spotify chief economist Will Page presents evidence from case studies that artists who withhold their music from Spotify do not sell more copies. This suggests

\footnotetext{
${ }^{8}$ https://news. spotify.com/us/2014/11/11/2-billion-and-counting/.
} 
that Spotify does not cannibalize sales at the artist level. ${ }^{9}$

\subsection{Streaming as Bundled Selling}

While sales stimulation is sufficient to demonstrate a positive impact of streaming on revenue, a negative impact of streaming on permanent sales - sales displacement - is not sufficient to demonstrate that streaming reduces revenue. Because Internet radio services pay rights holders for streams, the effect of streaming on revenue depends on the rate of sales displacement.

To say this another way, streaming services present bundled offerings that allow the seller to collect revenue in circumstances that generated no revenue under a la carte selling. It is well known that bundling creates opportunities to raise revenue, particularly when the products have zero marginal costs. ${ }^{10}$ Consumers' decisions to purchase a bundle depend on the sum of their valuations across songs. Hence the valuation coming from songs that a consumer values too little to purchase a la carte will not raise revenue under a la carte selling, while it can contribute to revenue under bundling.

The most salient example of this kind of revenue reclamation arises from streaming as an alternative to piracy. Spotify's Daniel Ek argues that while "piracy doesn't pay artists a penny," "Spotify has paid more than two billion dollars...... that's two billion dollars' worth of listening that would have happened with zero or little compensation to artists...... if there was no Spotify." 11 Academic studies have also documented that appealing licensed alternatives can depress piracy (Danaher et al., 2010, 2013). Ek's point that bundled sales through Spotify can harvest as revenue interest in music that would otherwise have animated piracy is correct, but that possibility alone does not imply that revenue to recorded music would.

\subsection{A Simple Model of a la Carte and Bundle Music Purchase}

It is helpful to articulate a simple model of music purchase under a la carte and bundled options to characterize the possible impacts of streaming on sales. In the absence of a streaming bundled offering, consumers have three choices with each song. They can purchase it at its a la carte price, they can obtain an unauthorized copy without payment (piracy), or they can forgo its

\footnotetext{
${ }^{9}$ See Page (2013) (https://press.spotify.com/us/2013/07/17/adventures-in-netherlands/). But David Lowery is characteristically blunt about the opposite conclusion, arguing that "Spotify doesn't kill music sales like smoking doesn't cause cancer..."

${ }^{10}$ See Bakos and Brynjolfsson (1999).

${ }^{11}$ https://news . spotify.com/us/2014/11/11/2-billion-and-counting/.
} 
consumption ("suffering in silence"). For concreteness, suppose that each consumer $i$ has a valuation of the song $v_{i}^{s}$, along with a non-monetary cost of piracy that is specific to the person and song, $g_{i}^{s}$. The song has an a la carte price $p$.

The consumer purchases the song if his valuation of the song exceeds the price and the price is lower than the non-monetary cost he would experience from obtaining the song, i.e. if $v_{i}^{s}>p$ and $p<g_{i}^{s}$. The consumer pirates the song if his non-monetary cost is lower than the price and his valuation exceeds the non-monetary cost, i.e. if $v_{i}^{s}>g_{i}^{s}$ and $p>g_{i}^{s}$.

There are two ways for a consumer to fail to consume a song he values positively under a la carte. First, if the price is below the individual's non-monetary cost of obtaining the song $\left(p<g_{i}^{s}\right)$, so that purchase would be the preferred mode for obtaining this song, then the individual forgoes consumption if the value falls short of the price. Second, if unpaid consumption would be the individual's preferred mode of acquisition for this song, then the non-monetary cost falls short of the price $\left(g_{i}^{s}<p\right)$, and the individual forgoes consumption if the value falls short of the non-monetary cost of obtaining the song.

With this setup the consumer surplus that individual $i$ experiences from songs $s=1, \ldots, N$ is $v_{i}^{s}-p$ for each of the songs he buys and $v_{i}^{s}-g_{i}^{s}$ for each of the songs he obtains without payment. Formally:

$$
C S_{i}=\sum_{s}\left[\left(v_{i}^{s}-p\right) \mathbf{1}\left\{v_{i}^{s} \geq p ; p<g_{i}^{s}\right\}+\left(v_{i}^{s}-g_{i}^{s}\right) \mathbf{1}\left\{v_{i}^{s} \geq g_{i}^{s} ; p>g_{i}^{s}\right\}\right]
$$

The revenue that the sellers derive from the consumer is the number of instances in which he purchases, times the price:

$$
\operatorname{Rev}_{i}=p \sum_{s} \mathbf{1}\left\{v_{i}^{s} \geq p ; p<g_{i}^{s}\right\}
$$

The deadweight loss associated with the consumer arises from the instances in which the valuations exceed the (zero) marginal cost but no consumption occurs:

$$
d w l_{i}=\sum_{s}\left[v_{i}^{s} \mathbf{1}\left\{v_{i}^{s}<p ; p<g_{i}^{s}\right\}+v_{i}^{s} \mathbf{1}\left\{v_{i}^{s}<g_{i}^{s} ; p>g_{i}^{s}\right\}\right]
$$

The advent of streaming allows different consumption possibilities and, importantly, different 
revenue opportunities. In particular, streaming allows the possibility of revenue generation from circumstances generating no revenue under a la carte sales. When streaming replaces piracy, this revenue is new; and when streamed consumption replaces situations in which non-pirates would have forgone consumption, the revenue is new. However, when streaming replaces a la carte purchase, the streaming revenue comes at the expense of a previous revenue stream. Hence, generating revenue from instances which formerly did not generate revenue - such as piracy - is not sufficient for streaming to raise revenue.

To see how streaming might affect revenue, it is useful to articulate a model of the decision to purchase the streaming service. Define $p_{B}$ as the price of the bundle. Consumer $i$ purchases the bundle if the surplus he obtains from the bundle is positive and exceeds the surplus he obtains from his chosen combination of purchase and stealing. $C S$ under streaming is

$$
C S_{i}^{\text {Streaming }}=\sum_{s} v_{i}^{s}-p_{B}
$$

Hence, consumer $i$ purchases the bundle if his surplus under streaming exceeds his surplus under a la carte purchase, or if:

$$
\sum_{s} v_{i}^{s}-p_{B}>\sum_{s}\left[\left(v_{i}^{s}-p\right) \mathbf{1}\left\{v_{i}^{s} \geq p ; p<g_{i}^{s}\right\}+\left(v_{i}^{s}-g_{i}^{s}\right) \mathbf{1}\left\{v_{i}^{s} \geq g_{i}^{s} ; p>g_{i}^{s}\right\}\right]>0 .
$$

A figure helps to explain this. Figure 2a shows a consumer's valuation of all songs he values positively. We can represent these valuations as a demand curve, where we order the songs from most highly valued to least. The gray area under this demand curve is the consumer surplus he would experience if all songs were free. This area less the bundle price $p_{B}$ is the surplus experienced under bundling if he chooses the bundled option.

Songs can be divided for this individual into those he would be willing to steal (with $g_{i}^{s}<p$ ) and those he would not steal $\left(p<g_{i}^{s}\right)$. His valuation distributions are represented under the second (Figure 2b) and third (Figure 2c) demand curves (note that the area under the second and third demand curves sums to the area under the first). Revenue under the a la carte regime is the dark gray rectangle under the buy $\left(p<g_{i}^{s}\right)$ curve, while consumer surplus under a la carte is the sum of $C S_{1}$ for songs with $g_{i}^{s}<p$ and the $C S_{2}$ for songs with $g_{i}^{s}>p$.

Suppose that the streaming option were available at a price $p_{B}$ equal to the amount that the individual formerly spent on a la carte music (the revenue under the "buy" demand curve). 
Then he would clearly prefer the bundled option because the bundled option would deliver more $C S$ than a la carte (the bundled $C S$ would equal to the full area under the demand curve less the a la carte revenue). Hence, all of the other regions under both demand curves would become consumer surplus.

While the consumer described above - and illustrated in Figure 2 - would prefer the bundle if priced appropriately, not all consumers would prefer the bundle. For example a consumer for whom $g_{i}^{s}=0$ for all songs would obtain the full area under the demand curve in Figure 2a as $C S$ by stealing everything a la carte. This would exceed his surplus from purchasing the bundle.

In our model, if $p_{B}$ is equal to a la carte revenue, then the consumer chooses the bundle. It's worth noting that revenue from streaming is not literally $p_{B}$. Instead, rights holders are paid a per-stream rate times the number of times their songs stream. We are implicitly assuming that $p_{s} S$ is related to $p_{B}$, for example that the streaming payments equal the subscriber revenue less administrative fees. How bundle revenues are shared among rights holders is the topic of a small economic literature. See Ginsburgh and Zang (2003) and Shiller and Waldfogel (2013).

Assuming that individuals not adopting streaming do not steal different amounts when the bundled option becomes available, whether streaming raises revenue depends entirely on the revenue gains and losses from those adopting streaming. All of the revenue from consumers who formerly specialized in piracy is gain. Similarly, the revenue from the units that paying consumers failed to consume (because $v_{i}^{s}<p$ ) is a gain. But the revenue from units formerly purchased at $p$ per unit by a la carte buyers is now gone, replaced by the revenue from the streaming subscription fee.

It is clear from this simple model that the change in revenue under bundled sales comes from four conceptually distinct sources. The first three are gains under streaming, while the fourth is a loss. The first source of revenue is the units that were formerly consumed without payment. The second source consists of units that were formerly not consumed, despite that fact that the non-monetary cost is below the price $\left(g_{i}^{s}<p\right)$, because the valuation falls short of even the non-monetary cost of acquisition $\left(v_{i}^{s}<g_{i}^{s}\right)$. A third source of revenue is units that were formerly not purchased, despite the fact that the price falls short of the non-monetary cost $\left(p<g_{i}^{s}\right)$, because the value falls short of the price $\left(v_{i}^{s}<p\right)$. The final source of changed revenue is the reduction in a la carte revenue for units which were formerly purchased at $p$ (where $v_{i}^{s}>p$ and $p<g_{i}^{s}$ ), but now generate revenue only as part of the payment for streaming. For revenue 
to rise, it is necessary that the additional revenue collected for units not formerly generating revenue offset any reduction in revenue from the songs formerly purchased a la carte.

This setup points to various possible impacts of bundled sales through streaming. First, it is possible that streaming would reduce unpaid consumption. Second, it is possible that streaming would reduce the instances of failure to consume songs whose value exceeds zero to their potential users. Finally, it is also possible that streaming would displace paid a la carte sales. Of these three, two are observable to us, the volume of unpaid consumption and the volume of paid a la carte permanent downloads.

\subsection{Recent Growth of Internet Radio as an "Experiment"}

Pandora was founded in 2000. ${ }^{12}$ As the top-right panel in Figure 3 shows, Pandora grew quickly from 2008 to 2012: annual listening hours rose from 0.9 billion on 2008 to 14 in 2012, roughly doubling each year. In 2014, annual listening hours stood at 20 billion. Growth in Pandora's use continues, but it is steady. YouTube has been a significant provider of music streams since 2009. Its worldwide growth during 2013 is steady, as the bottom-right panel of Figure 3 shows. ${ }^{13}$

Spotify was founded in 2006. It too has grown quickly, particularly since 2013. Between January 2012 and January 2015, total global users quadrupled; paid users rose by a factor of five over that period. As of late 2014 Spotify had 15 million paid users. See top-left panel in Figure 3. By early 2015 Spotify had 60 million users overall. See bottom-left panel in Figure 3.

The growth of streaming is also visible in the US recorded music industry's revenue data. The Recording Industry Association of America (RIAA) reports data on revenue from the sales of recorded music as well as streaming. ${ }^{14}$ In 2010 US streaming revenue stood at $\$ 0.5$ billion. By 2012 streaming revenue reached $\$ 1.0$ billion, and by 2013, streaming revenue rose to $\$ 1.4$ billion. US streaming revenue reached $\$ 1.9$ billion in 2014. Streaming revenue is broken into three components, SoundExchange distributions (which are largely payments from Pandora), revenue from subscription services (which is largely Spotify), and payments from "on-demand ad supported" streaming services such as YouTube. In 2014, SoundExchange revenue made up 41 percent of total streaming revenue, subscription revenue made up 42 percent, and on-demand ad supported revenue made up the remaining 17 percent.

\footnotetext{
${ }^{12}$ http://en.wikipedia.org/wiki/Pandora_Radio.

${ }^{13}$ We obtained weekly aggregate video views on YouTube for 2012-2013 from Musicmetric.

${ }^{14}$ See Joshua P. Friedlander, News and Notes on 2014 RIAA Music Industry Shipment and Revenue Statistics, RIAA http://riaa.com/media/D1F4E3E8-D3E0-FCEE-BB55-FD8B35BC8785.pdf.
} 
It seems clear that the music industry is living through a large-scale "experiment" as Spotify's streaming service diffuses rapidly, particularly during 2014. This raises the possibility of studying the impact of this diffusion on the sales of recorded music. Given that our sales data cover 2012-2013 (and through early 2015 for the US), Spotify growth is the streaming growth "experiment" that we can study.

\section{Data}

Historical circumstances dictate the data that would be most suitable for documenting the impact of streaming on sales. We have seen rapid growth of streaming at Spotify in 2013 and especially during 2014. Ideally, then, we would observe volumes of Spotify streams over time for separate groups of consumers differing in their timing or extents of Spotify adoption. We would also observe their volumes of recorded music purchase as well as their volume of piracy consumption. Importantly, we would need to observe all of these factors for the period of the "experiment," the rapid Spotify adoption period of 2012-2014.

The actual data available to us fall short of the ideal but nevertheless offer some promise of identification of the effect of interest. Rather than total Spotify streams, we observe the volume of streams for each of the top 50 songs by week and by country during the period covering April 2013 - March 2015 (top 200 beginning in October 2014). ${ }^{15}$ If the volume of streams at the top of the distribution mirrors that of the whole distribution, then we have a reasonable index of total streaming. We are not able to check the correlation of the top 50 streams with total streams, but we can compare it to the top 200 (for the period October 26, 2014-March 8, 2015). If we aggregate weekly top 50 and top 200 streams across sample countries, the correlations for the 21 -week overlap period is 0.99 , suggesting that the top-50 index is a valid measure of total Spotify use.

To see how the top 50 relates to the unobserved total number of streams we need a quick forensic detour into Spotify's publicly announced payouts and payout rates per stream. See Table 1. According to Spotify, their per-stream payout to rights holders is "between $\$ 0.006$ and $\$ 0.0084 . " 16$ Given that Spotify paid out $\$ 1$ billion to rights holders in 2014 , one can calculate that they delivered between 119 and 167 billion streams worldwide in 2014, where a stream is a performance of a song for an individual listener). Dividing by 52 , this translates to between

\footnotetext{
${ }^{15}$ As of March 8, 2015 Spotify has discontinued the release of these data.

${ }^{16}$ See "Spotify explained," at http://www.spotifyartists.com/spotify-explained/.
} 
2.3 and 3.2 billion streams per week. Spotify reported weekly top 50 worldwide streams of 247 million in November 2014. ${ }^{17}$ The top 200 worldwide streams totaled 469 million in the same week. Hence, the top 50 worldwide streams account for between 7.7 and 10.8 percent of total streams, and we can roughly translate the top-50 streaming index into total streams by multiplying it by 11.2 (the midpoint between 1/.077 and 1/.108). Figure 4 shows our Spotify top 50 streaming index by country, normalized to show growth. The graphs also include a vertical line at the start of 2014. It is clear that much of the growth occurs after 2013.

We have weekly data on digital recorded music sales for 21 countries for 2012-2013 from Nielsen. This is useful in that it allows us to compare Spotify use and recorded music sales in places with different Spotify use growth patterns. Unfortunately, the overlap period is only about 8 months. Moreover, it predates the period of most rapid growth in Spotify use during 2014. The digital music sales data however include both song-level and aggregate information for the years 2012-2013. We can therefore merge these data, by country and week, with song-level Spotify streams of popular songs appearing on the top 50 or top 200 lists to attempt measure sales displacement at the song level. We also have access to data on weekly aggregate sales of recorded music from the US from Billboard Magazine, in its weekly charts section. Fortunately, this data extends beyond the end of 2013 through the end of the Spotify coverage in March 2015. Reported measures include digital track sales, digital album sales, and physical album sales. Separate data on digital tracks vs digital or physical albums may be useful for identifying impacts of streaming on sales. It is plausible to think that users of streaming would otherwise be purchasers of digital music, particularly singles. If so, then streaming would be a better substitute for digital single sales than, say, the sales of physical albums.

Finally, we have data on music piracy from Musicmetric. These data cover the weekly volumes of piracy via torrents for 8,000 top artists in all of our sample countries, 2012-2013. Hence, as with the music sales data, we have overlap with Spotify for the period April-December 2013. We can match these data with artist-level Spotify streams, by country and week, and attempt to estimate piracy displacement at the artist level for the most popular artists.

Summarizing, we have drawn data for this study from four sources. First, we have two sources of data on music sales. We have Nielsen weekly digital sales data for 21 counties for the period 2012-13. These countries include the US, Canada, and 19 European countries. Second, we have aggregate US weekly physical and digital sales data for 2013 through March, 2015. Third,

\footnotetext{
${ }^{17}$ See http://charts. spotify.com/?object=tracks\&rank=most_streamed\&country=global\&windowtype=we ekly\&date=latest.
} 
we have weekly streaming data for the top 50 songs at Spotify, by country and week, for the matched set of countries, for the weeks April 28, 2013 - March 8, 2015. Fourth, we have data on the volume of unpaid consumption via torrents for 8,000 top artists from Musicmetric.

\section{Estimation Approaches}

The challenges in estimating the impact of streaming on the sales of recorded music or piracy recall the challenges in measuring the sales-displacing impact of piracy on music sales.

\subsection{Song and Artist-level approaches}

Using song-level data by country and week, we can attempt to identify the sales displacement coefficients in a variety of ways. We bear in mind even at the outset that the song-level approach faces two substantial challenges. First, streaming of particular songs is endogenous. Second, even if one were to uncover a credible causal impact at the song level, it would not necessarily reflect the effect of interest, the overall impact of streaming on sales.

Define $q_{s c t}$ as the sales of song $s$ in country $c$ and week $t$. Define streams $s_{s c t}$ analogously. It is instructive to consider the sequence of possible approaches, including those with little promise of credibly identifying the causal impact of streams on sales, to understand the possible promise of other approaches. The generic endogeneity challenge is that streaming and sales may both be driven by the time-varying interest in a song. Consider, first, the simplest approach:

$$
q_{s c t}=\alpha_{0}+\alpha_{1} s_{s c t}+\varepsilon_{s c t}
$$

This approach has little promise of identifying possibly displacing effects of streaming on sales, for three clear reasons. First, streaming and sales will both be higher in larger countries. Second, they will both be higher for songs that are more popular. Third, both may be higher at times of high sales (e.g. holidays).

Taking one step at a time, if we add country fixed effects to this specification, yielding: $q_{s c t}=$ $\alpha_{0}+\alpha_{1} s_{s c t}+\mu_{c}+\varepsilon_{s c t}$, then we will have dealt with the problem that some countries are larger than others. We can include fixed effects for country, song, and calendar weeks. The identification strategy is then, in words, to ask whether songs that stream more in this country 
and week, relative to the average levels for this country, song, and week, sell more during this week.

This approach is still vulnerable to the concern that interest in a song has a song-specific temporal component. For example, a few weeks after release, a particular song may be of interest to consumers via both channels (purchase and streaming). We can attempt to address this by including song-specific time effects:

$$
q_{s c t}=\alpha_{0}+\alpha_{1} s_{s c t}+\mu_{c}+\theta_{s t}+\varepsilon_{s c t} .
$$

This approach allows for a song-specific time pattern of sales that is common across countries, then asks whether song-country-weeks with more streaming have higher or lower sales.

The song-specific approach recalls the approaches of Oberholzer-Gee and Strumpf (2007) and Blackburn (2004) in the file-sharing literature. Both of those studies relate the volume of unpaid consumption for particular works over time to the volume of recorded music sales for the same works. Oberholzer-Gee and Strumpf (2007) also employ an instrumental variables approach, based on the number of German school children on vacation, to generate exogenous variation in the volume of unpaid activity.

We attempt to identify the piracy displacement using artist-level data on unpaid consumption and streaming by country and week. We can go as far as introducing artist-specific time effects (along with country fixed effects) in a regression of unpaid consumption on streams. We can therefore ask whether artist-country-weeks with more streaming have higher or lower levels of unpaid consumption, after controlling for artist-specific time patterns of piracy.

\subsection{Aggregate Approaches}

It is arguable that the aggregate approach holds more promise than the song-specific approach. Suppose that streaming is growing because it is new and has not yet diffused. Then the change in streaming is not related to the appeal of music. Rather, the change in streaming is effectively exogenous. Its diffusion effectively acts as an experiment, and we can measure its effect by looking at what happens to sales during the diffusion. Contrast that with the song-level approach. Ideally, the song level approach would be driven by the possibility that some songs are heavily streamed while others are not, for reasons unrelated to the appeal of the songs. This would work, for example, if there some set of songs appealed to consumers who do not use 
streaming, while another set of songs appealed to consumers who use streaming. Given that we only observe streaming volumes for the most popular songs, we cannot implement this approach, even if we had a notion of which songs do and do not stream extensively. This leaves us with the impression that the aggregate approach holds more promise of identifying the impact of streaming on sales.

Our basic approach to measuring the impact of Spotify streaming on sales and piracy, using the multi-country dataset, is to regress weekly measures of sales (and piracy) on country dummies, week dummies, and a measure of Spotify streaming in the country:

$$
q_{c t}=\gamma_{c}+\gamma_{t}+\alpha s_{c t}+\varepsilon_{c t}
$$

where $q_{c t}$ is a measure of consumption (sales or piracy) in country $c$ during week $t, s_{c t}$ is a measure of Spotify streaming in country $c$ in year $t, \gamma_{c}$ and $\gamma_{t}$ are country and week fixed effects, respectively, and $\varepsilon_{c t}$ is an error term.

The basic approach to measuring sales displacement in the Billboard US-only data for 2013 through March 2015 is slightly different, since the data are weekly for a single country. We cannot employ an arbitrary week dummy. We can, however, use a week of the year dummy to adjust for seasonality, since we have weekly observations for more than two years. With this approach, we are asking whether sales this week in the US move with the volume of streaming, after accounting for seasonality.

We have a second possible approach to identification using the Billboard US aggregate data. We observe aggregate sales separately for three modes of selling recorded music: digital singles, digital albums, and physical albums. Roughly speaking, digital track sales average 22 millions per week during the sample, compared with 5 million and 2 million for physical and digital albums, respectively (see Table 3). Keeping in mind that albums contain about 10 tracks, the track-equivalent volume of sales through these modes are 22 million for digital singles, 50 million for physical album tracks, and 20 million for digital album tracks. If consumers of physical albums did not use streaming music, then we could view physical album sales as very effective proxy for digital track sales. 


\section{Results}

\subsection{Song and Artist-level Results}

The Spotify data for April-December 2013 contain a total of 1,241 songs. We are able to match the appearances of these songs in Spotify with their appearances in Nielsen sales data for the same country weeks. Of these, we matched the 714 songs with the most song-week observations, resulting in a dataset with 24,538 country-week-song observations on sales and streaming.

The first panel in Table 4 reports results of regressions using the song-level data. Regardless of which set of fixed effects we include, we find a positive coefficient on streams, in the neighborhood of 0.07 . This coefficient indicates that songs that stream an additional 14 times sell one more copy. Note that this result obtains even when we use song-specific time dummies. So the result means that after accounting for the temporal popularity of this song (in a common way across countries), as well as the different tendencies to purchase songs in different countries, country weeks in which a song streams more it also sells more.

There are two possible interpretations. One is that streams stimulate sales. A second possibility is that the relationship is contaminated by unobserved heterogeneity. Songs that are popular in particular countries during particular weeks are both streamed and sold at elevated rates. So we are left with something best described as questionable evidence for song-level sales stimulation. And even if streaming stimulates sales at the song level, it is not clear that the overall effect of streaming on sales would be positive.

While we do not have access to song-level piracy data, we can perform artist-level regressions by matching artists across the streaming and unpaid consumption datasets. We are able to match 279 artists, which overall account for 85\% of the streams in our April-December 2013 Spotify data. The second panel in Table 4 reports artist-level regressions, and we obtain results similar to the results on purchase. Artists that are streaming more on Spotify this week tend also to be pirated more this week, after accounting for the various fixed effects.

\section{$5.2 \quad$ Aggregate Results}

We have two aggregative approaches to measuring sales and piracy displacement using the 21country data for April-December 2013. One approach is to aggregate the sales, piracy, and streams by country week for the songs and artists we were able to match in the Spotify data, 
which we refer to as "matched aggregate" sales, piracy, and streams. A second approach is to link overall sales and piracy (aggregating across all songs, not just those we can match in Spotify) with our index of Spotify streaming, the sum of the streams of the top 50 songs by country week.

We are interested in the rates of sales and piracy displacement, the change in sales and piracy with a one-unit increase in streaming. It is important to recall that top-50 Spotify streams represent only a fraction of total Spotify streams, so we need to divide the coefficient from the aggregate regressions by 11.2 in order to obtain an estimate of the per-stream sales and piracy displacement rates.

The first panel in Table 5 reports regressions of matched aggregate sales by country week on matched aggregate streams. When we do not include fixed effects, in column (1), the sales displacement coefficient is positive. When we include a country fixed effect, in column (2), the coefficient becomes negative (-0.024, with a standard error of 0.005$)$. The coefficient in the specification with fixed effects for week as well as country, in column (3), is nearly identical. When we include only US data (and therefore no country nor time fixed effects), the coefficient is -0.0363 (0.026) (column (4)). Including a time trend, in column (5), changes the displacement coefficient to $-0.0659(0.034)$.

The second panel in Table 5 does an analogous exercise using total weekly digital sales by country as the dependent variable and the top-50 Spotify index on the right-hand side, again for the period April - December, 2013. Column (1) includes neither country nor week dummies, and the displacement coefficient is positive. Column (2) includes country dummies, and the resulting displacement coefficient is -0.21 (standard error of 0.03). Column (3) adds week dummies, and the resulting displacement coefficient is -0.23 (0.03). If top-50 Spotify spins are $1 / 11.2$ of total Spotify spins, then the coefficients indicate that an additional Spotify spin reduces sales by 0.023 , or that is takes 43 Spotify spins to reduce digital track sales by 1 . The last two columns of the table report sales displacement coefficients for only the US using the 2013 data. Column (4) presents a coefficient of $-0.38(0.16)$, and including a time trend changes the coefficient to -0.45 (0.199), suggesting that the US variation in the multi-country panel is important for identifying the displacement coefficient. Indeed, when the US is excluded, the displacement coefficient is $0.01(0.004)$.

The first panel in Table 6 reports regressions of matched aggregate unpaid consumption activity on matched aggregate Spotify streaming. When no fixed effects are included in column (1), 
the piracy displacement coefficient is positive and significant. The inclusion of country fixed effects leads to a negative coefficient, and additionally including weekly fixed effects leaves the displacement estimate nearly identical. Using only the US data (therefore without country or week fixed effects), we obtain a much larger coefficient (-0.1237, with a standard error of 0.0328). Including a weekly time trend nevertheless reduces the coefficient by half $(-0.0643$, standard error of 0.0331).

The second panel in Table 6 reports regressions of total weekly unpaid consumption on the top-50 weekly Spotify streaming index. Again, the coefficients from all specifications except those excluding country fixed effects show clear evidence of piracy displacement. According to these results, and additional 47 streams reduces by one the number of tracks obtained without payment. This piracy displacement is consistent with Ek's claim that Spotify's bundled offering harvests revenue from consumers who - or at least from consumption instances - which were previously not generating revenue. While this evidence is consistent with successful bundling, it is not sufficient to demonstrate successful bundling. That, instead, depends on the overall impact of Spotify on revenue, which depends largely on its impact on permanent downloads.

Table 7 turns to the US-only data from Billboard covering both the last 9 months of 2013 along with 2014 and early 2015. The ex ante appeal of this exercise is that it covers a period of substantial growth in Spotify use in the US. These regressions relate total track sales to top 50 Spotify streams, so the coefficients must be divided by 11.2 to yield per-stream displacement rates. The first two columns examine digital track sales and show a displacement coefficient of -0.0813 (with a standard error of 0.007 ). This is substantially smaller than the degree of sales displacement implied by the 2013 relationship. Given that total Spotify streams are 11.2 times top-50 Spotify streams, this coefficient indicates that an additional overall Spotify spin reduces digital track sales by 0.0072 . The remaining columns of Table 7 present the analogous specifications for physical and digital albums, respectively. One in two of these coefficients is statistically significant.

The second panel of Table 7 revisits the regressions in the first panel of the table using log-log specifications. The digital track coefficient is $-0.21(0.01)$, while the physical and digital album coefficients are $-0.10(0.03)$ and $-0.07(0.03)$, respectively. All three of these coefficients are significantly different from zero.

Summing up, we see the following patterns. First, when we use aggregate data, we find sales and piracy displacement by Spotify. Second, when we use data on the US covering the period 
of substantial change in Spotify use, we find smaller sales displacement than when we use 2013 data. Third, the coefficients relating Spotify use to recorded music sales differ by format. The coefficients for digital track sales are generally higher than the coefficients for albums, but many of the album coefficients are also negative and significant. Our best estimate indicates than an additional 137 streams displaces one track sale.

\section{How Large is the Revenue Displacement?}

\subsection{Impact of Spotify on Rights Holder Revenue}

Roughly, rights holders receive 70 percent of revenue from digital track sales. According to the RIAA, the average revenue per digital track sold was $\$ 1.174$ in 2014 . Given the 70 percent share that labels obtain from Apple, this is $\$ 0.822$ per track sold. Considering only digital track sales and revenue from Spotify, revenue is the sum of revenue from selling digital tracks and the revenue from Spotify spins. That is, $r e v=0.822 q_{d}+p_{s} S$, where $q_{d}$ is digital track sales, $p_{s}$ is the payment per stream, and $S$ is Spotify spins. The change in revenue with additional Spotify spins is thus: $\frac{\partial r e v}{\partial S}=0.822 \frac{\partial q_{d}}{\partial S}+p_{s}$, where $\frac{\partial q_{d}}{\partial S}$ is the rate of sales displacement between Spotify and digital track sales. Whether Spotify raises or reduces revenue depends on whether $\frac{\partial r e v}{\partial S}>0$ which, in turn, depends on the value of $\frac{\partial q_{d}}{\partial S}$ relative to $p_{s}$.

We can summarize the possible effects of streaming on revenue in a picture with the degree of sales stimulation/displacement $\left(\frac{\partial q_{d}}{\partial S}\right)$ on the horizontal axis and the payment per-stream $\left(p_{s}\right)$ on the vertical. Figure 6 graphs the revenue-neutral line, i.e. the combination of sales displacement rates and streaming payments that make bundling revenue-neutral: $\frac{\partial r e v}{\partial S}=0.822 \frac{\partial q_{d}}{\partial S}+p_{s}=0$. Revenue will therefore rise with streaming if $\frac{\partial q_{d}}{\partial S}>-\frac{p_{s}}{0.822}$. If streaming stimulates permanent sales, then we could classify streaming as promotion, and overall revenue would rise. If streaming displaces sales, but the per-stream rate is sufficiently high, then streaming is successful bundling. Finally, if streaming displaces sales but the per-stream rate is low, then streaming is unsuccessful bundling as it decreases overall revenue.

Spotify pays between $\$ 0.006$ and $\$ 0.0084$ per spin, or about $\$ 0.007$ per spin. Given our preferred estimate of the rate of sales displacement $(-0.0072)$ and a payout per stream of $p_{s}=\$ 0.007$, the growth in Spotify appears to be essentially revenue-neutral for rights holders. This result puts Spotify on the border between successful and unsuccessful bundling. However, given the potentially large value of bundled offerings to consumers, it is not clear that revenue neutrality 
is an indication of success. One might instead expect a valuable new offering to allow additional revenue appropriation for rights holders.

The magnitude of sales displacement is both of general academic and industry interest for understanding the evolution of revenue in the music industry. It is also of specific potential relevance to the licensing rates paid by Internet radio concerns to music labels. Music streaming on Internet radio is subject to two payments, a songwriting royalty as well as a sound recording royalty. In most of the world, terrestrial radio is also required to pay for the use of both rights, but US radio stations pay only the songwriting royalty. For example, Pandora pays $1.85 \%$ of its revenue to ASCAP and another $2.5 \%$ to BMI for songwriters.

The sound recording royalty is administered separately. Labels or their representatives may negotiate rates directly with streaming services such as Spotify or Pandora. And indeed, Merlin (an organization representing independent labels) and Pandora have a voluntary arrangement. By default, however, the rate that Pandora pays in the US for sound recording royalties is determined by a compulsory license administered by the Copyright Royalty Board. Currently, Pandora paid 0.11 cent per stream in 2012 and 0.14 cent in $2015 .{ }^{18}$ As presented above, Spotify's songwriting royalty rate is not publicly known, but it can be estimated from public data to be about 0.7 cent per stream.

The rates that labels would negotiate with streaming services presumably depend on streaming's impact on sales. The more that streaming cannibalizes sales, the higher the rates that songwriters and owners of sound recordings would presumably require. Hence, again, the importance of understanding the impact of streaming on sales.

\subsection{Bargaining over Licensing Fees in the Shadow of Piracy}

Whether the growth in streaming - and apparently concomitant decline in recorded music sales - would reduce revenue for creators and intermediaries depends on the revenues associated with individual sales and streams. While non-interactive streaming rates are determined by a compulsory license in the US, rates for interactive services are negotiated individually between labels and services.

Bundled services offer a wide variety of music and potentially high value to consumers, but appropriating this value is challenging. If the labels were to negotiate collectively, they could presumably capture much of consumers' willingness to pay as revenue. Two concerns remain,

\footnotetext{
${ }^{18}$ http://www.bloomberg.com/bw/articles/2012-12-20/pandora-is-boxed-in-by-high-royalty-fees.
} 
however. First, even if the labels were to negotiate as a monopolist, they face competition from piracy as an outside good. If the labels were to insist on fee requiring Spotify to charge, say $\$ 25$ per month, then perhaps its potential users would revert to piracy.

There is a second concern for the industry arising from the fact that music rights holders do not negotiate royalty rates collectively. Even if piracy were eliminated, the competition among labels would tend to reduce rates. Evidence above is at least suggestive that when particular songs are aired, they sell more than when they do not, even if music as a whole sells less when streaming exists. In such an environment it is easy to envision a prisoner's dilemma in which rights holders are better off charging low rates and getting their particular songs aired, even though they would be better off still if they all withheld their music from streaming services. Pandora's recent deal with Merlin, the representative of a large number of independent labels, provides an interesting example. Under the deal, Pandora "will recommend Merlin artists over those not affiliated with the consortium in exchange for paying Merlin's musicians a lower royalty rate." 19

A third possibility for the industry - the Taylor Swift option - is that rights holders might withhold their music from streaming services during periods of high demand. After an initial burst of a la carte sales around release, artists might make their works available to streaming services. This is a form of inter-temporal price discrimination. The viability of all of these approaches require first some understanding of the relationship between streaming and sales.

\section{Conclusion}

While song-level evidence, including a controlled experiment elsewhere on non-interactive streaming, show positive relationships between streaming and track sales, aggregate-level evidence indicates the opposite relationship, that interactive streaming at Spotify displaces track sales. Hence Spotify is better viewed as a form of bundled sales than as a promotional channel. Bundled sales of zero marginal cost products hold the promise of raising revenue, consumer surplus, or possibly both. Whether Spotify raises music-industry revenue depends on whether the additional revenues from streaming offset the reductions in revenues from permanent downloads. While we find evidence that Spotify displaces piracy, the new revenue generated through streaming payments (coming from formerly pirate consumers, buyers, or individuals that used to forgo

\footnotetext{
${ }^{19}$ Laura Sydell. "Pandora's New Deal: Different Pay, Different Play." NPR.org. November 26, 2014. http:/ /www.npr.org/2014/11/26/366339553/pandoras-new-deal-different-pay-different-play.
} 
consumption) is roughly offset by revenue reductions from the sale of permanent downloads.

This study provides a first step toward measuring the impact of interactive streaming's growth on music sales during 2014. Additional work would be helpful to provide more confidence in the answer. First, it would be desirable to conduct experimental studies at the song level for interactive streaming services to see whether they stimulate or depress track sales. Second, and perhaps more important, it would be desirable to find ways to study the impact of aggregate usage of non-interactive services on the overall sales of music, as a complement to this study's estimate of the impact of aggregate interactive streaming via Spotify on overall track sales.

Revenue generation from recorded music is shifting rapidly from the sales of individual tracks (and albums) to bundled sales of streams. As this transition continues, understanding the relationship between streaming and sales will be crucial to both our understanding, as well as the operation, of the recorded music industry. 


\section{References}

Adams, W. J. And J. L. Yellen (1976): "Commodity Bundling and the Burden of Monopoly," The Quarterly Journal of Economics, 90, 475-98.

BAKos, Y. AND E. BRYNJolfsson (1999): "Bundling information goods: pricing, profits and efficiency," Management Science, 1613-1630.

Blackburn, D. (2004): "Online Piracy and Recorded Music Sales," Unpublished manuscript, Harvard University.

Danaher, B., S. Dhanasobhon, M. D. Smith, and R. Telang (2010): "Converting Pirates Without Cannibalizing Purchasers: The Impact of Digital Distribution on Physical Sales and Internet Piracy," Marketing Science, 29, 1138-1151.

Danaher, B., M. D. Smith, and R. Telang (2013): "Piracy and Copyright Enforcement Mechanisms," in Innovation Policy and the Economy, Volume 14, National Bureau of Economic Research, Inc, NBER Chapters, 25-61.

Dertouzos, J. (2004): "Radio Airplay and the Recorded Music Industry: An Economic Analysis," National association of broadcasters, https://www.nab.org/documents/resources/ 061008_Dertouzos_Ptax.pdf.

Ginsburgh, V. And I. ZAng (2003): "The museum pass game and its value," Games and Economic Behavior, 43, $322-325$.

Hiller, R. S. AND J.-H. Kim (2014): "Online Music, Sales Displacement, and Internet Search: Evidence from YouTube," Working Paper.

Kretschmer, T. And C. Peukert (2014): "Video Killed the Radio Star? Online Music Videos and Digital Music Sales," CEP Discussion Papers dp1265, Centre for Economic Performance, LSE.

Liebowitz, S. J. (2004): "The elusive symbiosis: The impact of radio on the record industry," Review of Economic Research on Copyright Issues, 93-118.

McBride, S. (2014): "WRITTEN DIRECT TESTIMONY OF STEPHAN MCBRIDE (On behalf of Pandora Media, Inc)," http://www.loc.gov/crb/rate/14-CRB-0001-WR/sta tements/Pandora/13_Written_Direct_Testimony_of_Stephan_McBride_with_Figure 
s_and_Tables_and_Appendices_PUBLIC_pdf.pdf, Filed with Copyright Royalty Board, Washington, DC.

Oberholzer-Gee, F. And K. Strumpf (2007): "The Effect of File Sharing on Record Sales: An Empirical Analysis," Journal of Political Economy, 115, 1 - 42.

Page, W. (2013): "Adventures in the Netherlands: Spotify, Piracy and the new Dutch experience," https://press.spotify.com/ar/2013/07/17/adventures-in-netherlands/.

Schmalensee, R. (1984): "Gaussian Demand and Commodity Bundling," The Journal of Business, 57, S211-30.

Shiller, B. And J. WAldfogel (2011): "Music for a Song: An Empirical Look at Uniform Pricing and Its Alternatives," The Journal of Industrial Economics, 59, 630-660.

— (2013): "The Challenge Of Revenue Sharing With Bundled Pricing: An Application To Music," Economic Inquiry, 51, 1155-1165.

Stigler, G. J. (2007): "United States v. Loew's Inc. : a note on block-booking," Aus: Supreme court review ; 1 (1963), pp. 152 - 157.

VARIAN, H. R. (2000): "Buying, Sharing and Renting Information Goods," The Journal of Industrial Economics, 48, 473-488. 


\section{A Figures and Tables}

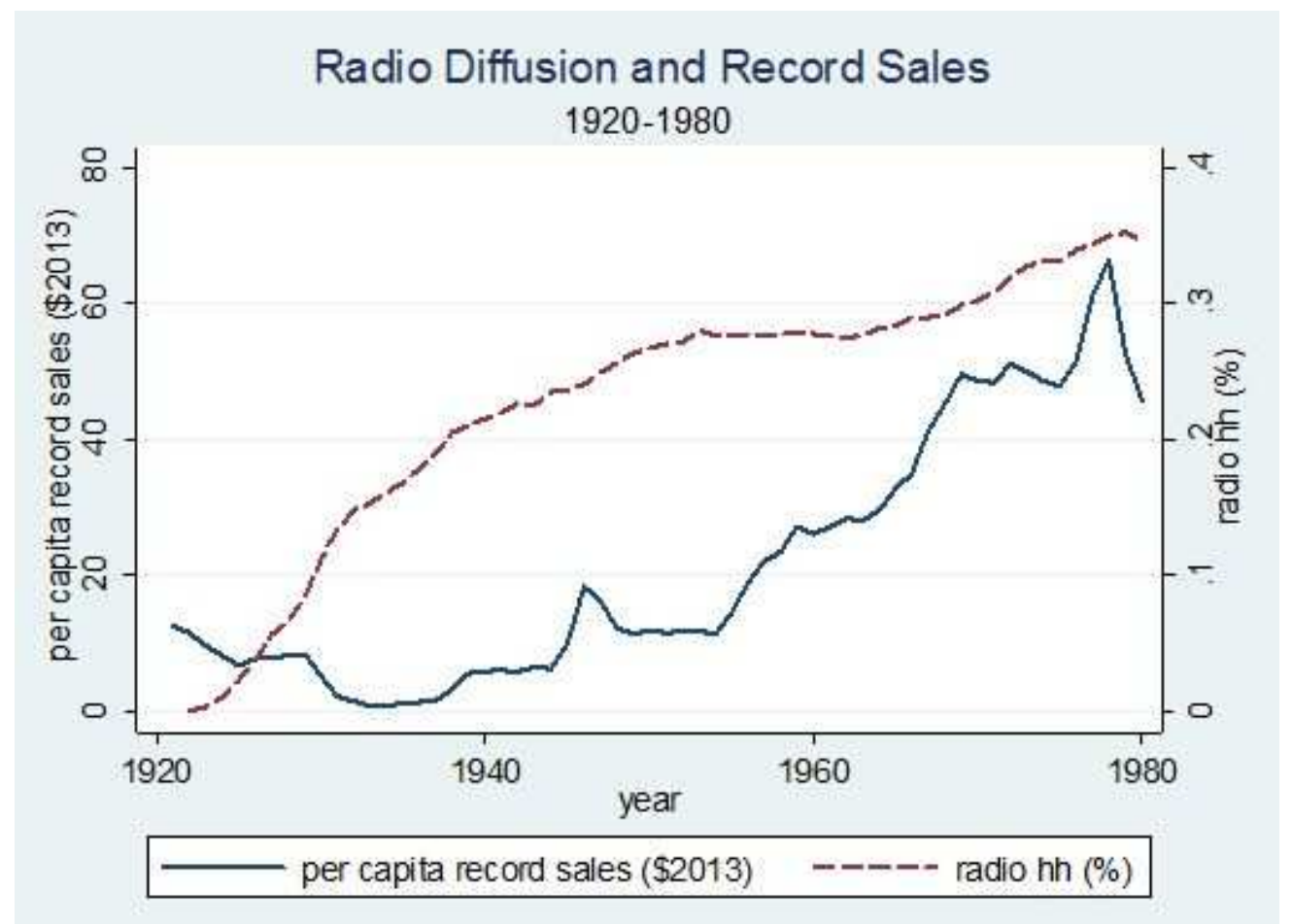

Figure 1: Radio Diffusion and Record Sales.

Figure 2: A Comparison of Bundle Purchase with a la Carte Consumption

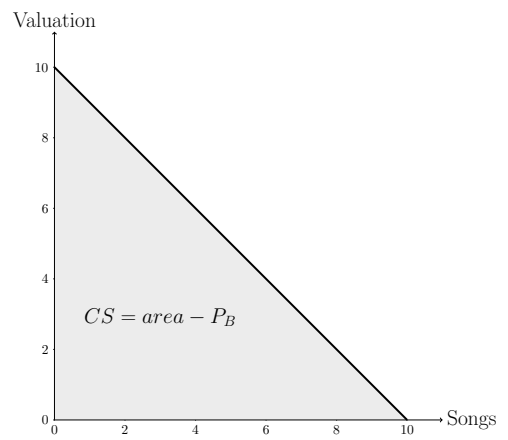

(a) Bundle

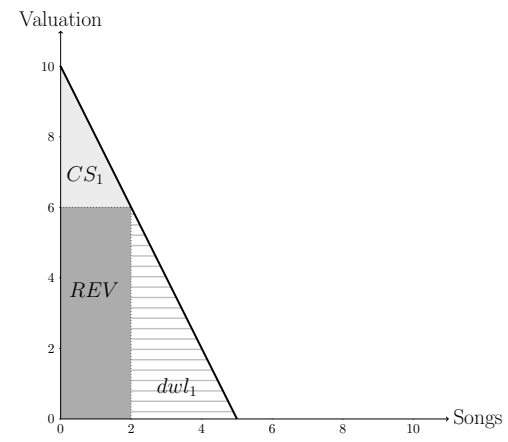

(b) A la Carte Buying: $p<g$

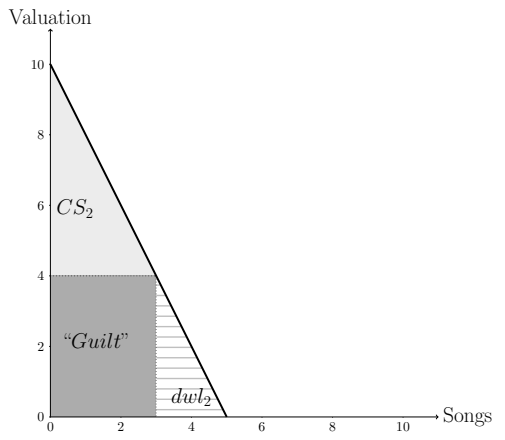

(c) A la Carte Stealing: $p>g$ 

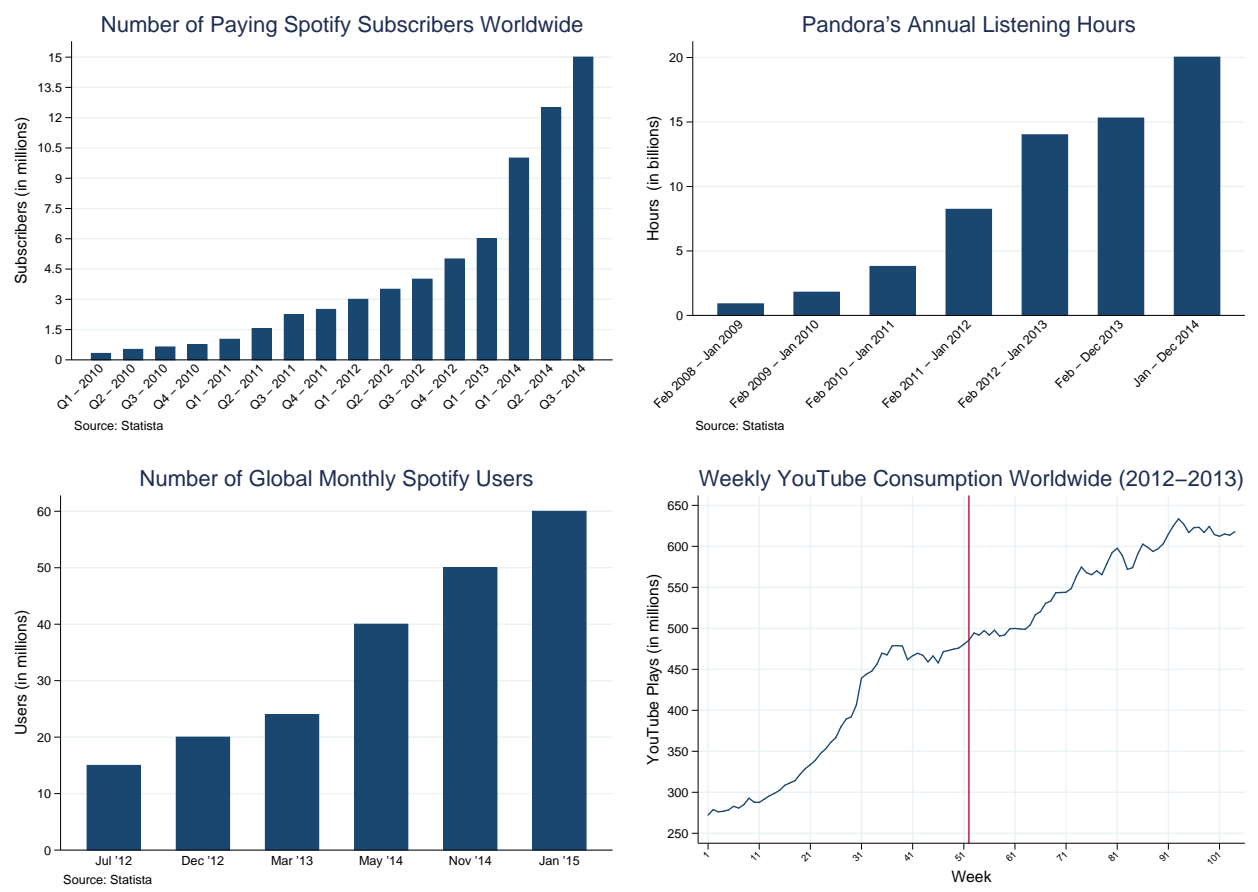

Figure 3: Evolution of Spotify's, Pandora's, and YouTube's Usage

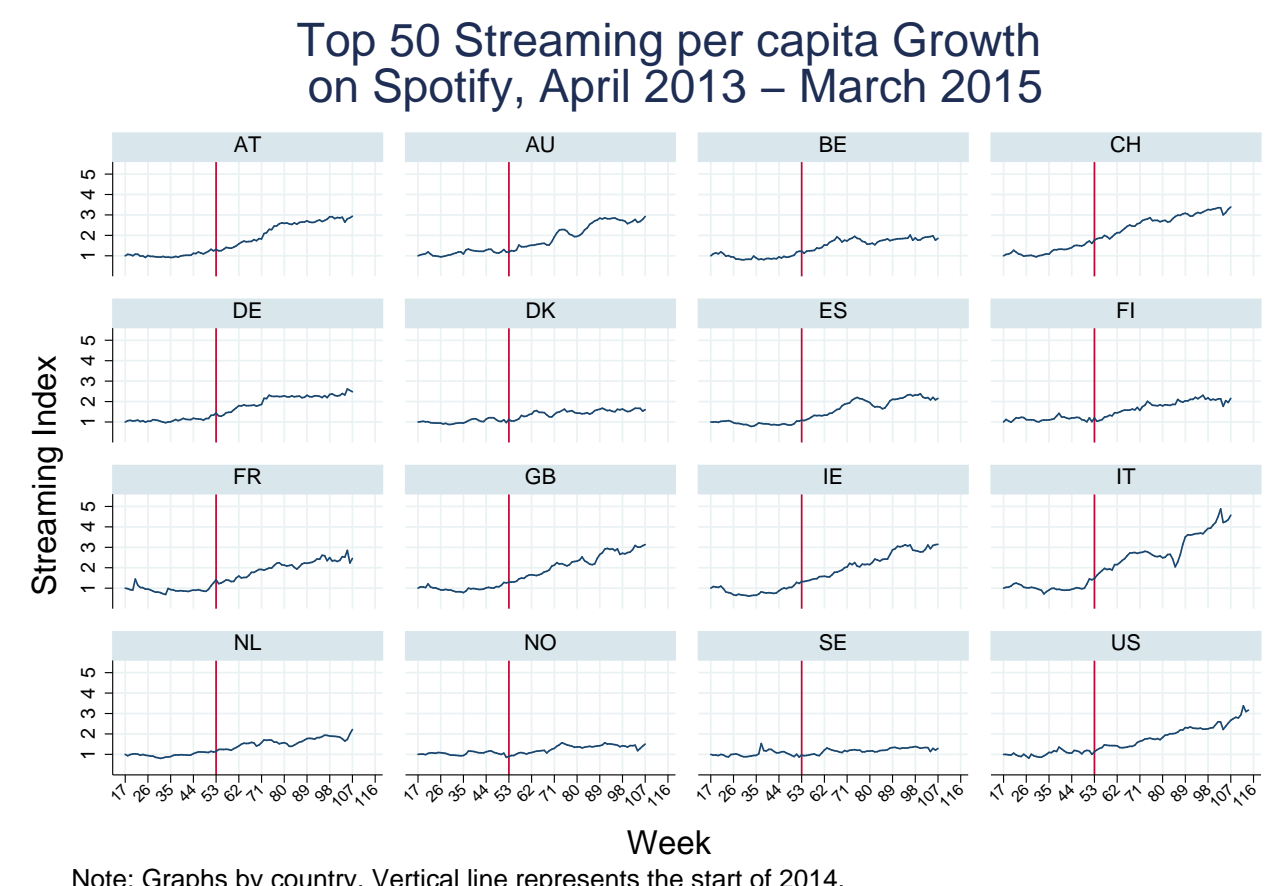

Note: Graphs by country. Vertical line represents the start of 2014.

Figure 4: Spotify's Per Capita Streaming Growth. 


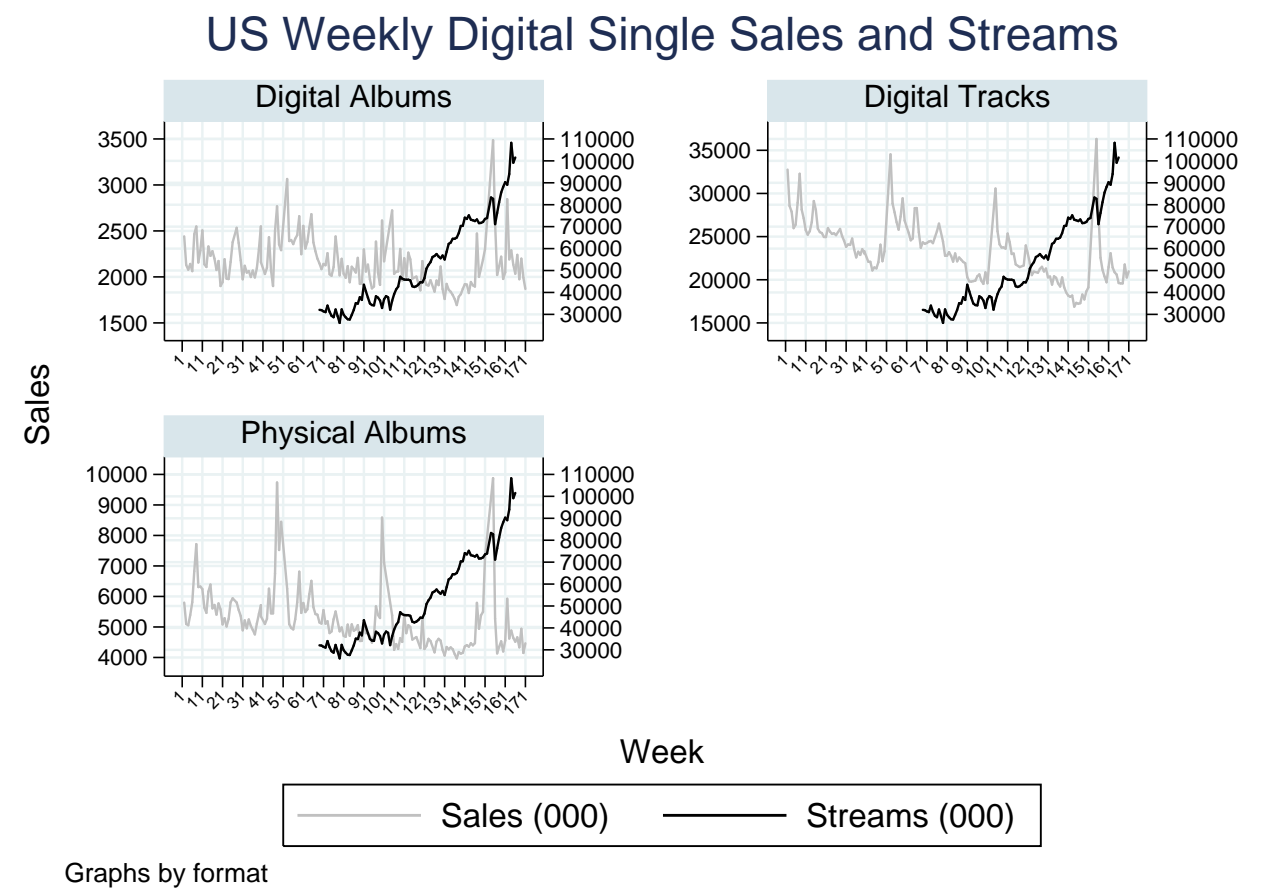

Figure 5: US Streams and Sales, by Format.

Figure 6: Displacement Rate and Price per Stream

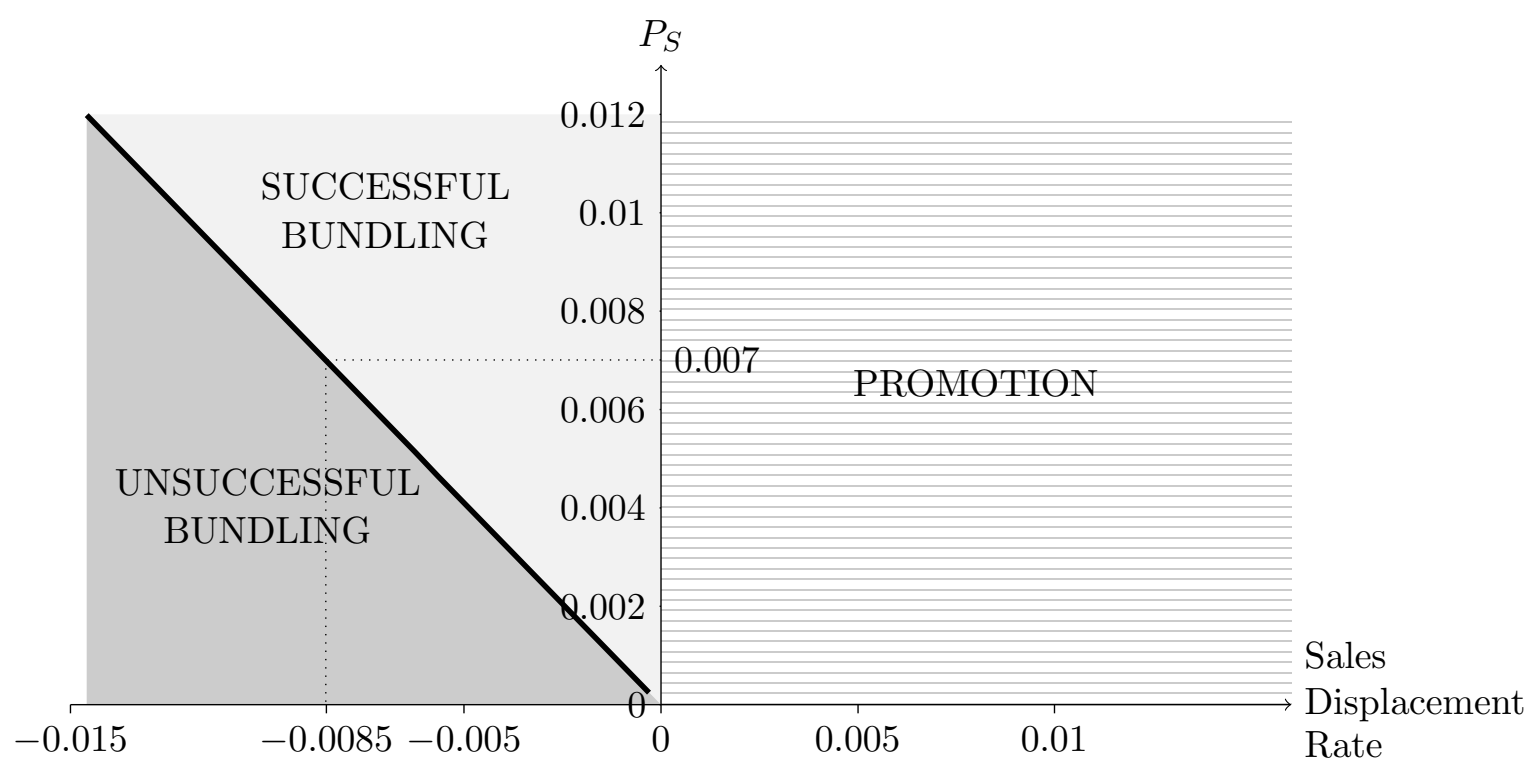


Table 1: Spotify's Payout

Spotify's 2014 payout $^{\dagger}$

Payout per spin

Yearly stream estimate

Weekly stream estimate $=$ yearly $/ 52$

Global weekly spins at head of distribution (Nov 2014)
$\$ 1,000,000,000$

$\$ 0.006 \quad$ High

$\$ 0.0084 \quad$ Low

166,666,666,667 High

119,047,619,048 Low

3,205,128,205 High

$2,289,377,289 \quad$ Low

$246,533,109$ top 50

$469,448,264$ top 200

$\dagger$ http://www.spotifyartists.com/spotify-explained/ 
Table 2: Sales and Streaming (April-December 2013). ${ }^{\dagger}$

\begin{tabular}{lccccc}
\hline \hline & \multicolumn{5}{c}{ Mean } \\
\cline { 2 - 6 } Country & Weekly Sales & $\begin{array}{c}\text { Weekly Spotify } \\
\text { Top 50 Streams }\end{array}$ & $\begin{array}{c}\text { Weekly } \\
\text { Streams/Sales }\end{array}$ & $\begin{array}{c}\text { Weekly Sales } \\
\text { per 1000 pop }\end{array}$ & $\begin{array}{c}\text { Spotify Top 50 } \\
\text { Streams per 1000 pop }\end{array}$ \\
\hline AT & 117.9 & 386.2 & 3.3 & 5.1 & 16.7 \\
AU & $1,637.1$ & $2,808.4$ & 1.7 & 193.2 & 331.4 \\
BE & 174.5 & $1,315.9$ & 7.6 & 15.6 & 117.5 \\
CH & 311.2 & 627.2 & 2.0 & 38.5 & 77.6 \\
DE & $1,347.8$ & $10,496.7$ & 7.8 & 16.7 & 130.2 \\
DK & 118.1 & $6,768.0$ & 58.4 & 21.0 & $1,205.6$ \\
ES & 141.2 & $7,410.2$ & 53.0 & 3.0 & 158.9 \\
FI & 26.4 & $3,869.7$ & 147.1 & 4.9 & 711.4 \\
FR & 687.2 & $2,251.3$ & 3.3 & 10.4 & 34.1 \\
GB & $3,144.0$ & $9,872.7$ & 3.2 & 49.1 & 154.0 \\
GR & 12.1 & 137.6 & 11.5 & 1.1 & 12.5 \\
IE & 101.1 & 520.7 & 5.3 & 22.0 & 29.3 \\
IT & 339.5 & $1,747.4$ & 5.2 & 5.7 & 5.5 \\
LU & 16.8 & 3.0 & 0.2 & 30.9 & 430.2 \\
NL & 160.4 & $7,229.4$ & 45.5 & 9.5 & $2,263.1$ \\
NO & 106.2 & $11,505.8$ & 109.4 & 20.9 & 196.6 \\
NZ & 171.3 & 878.8 & 5.2 & 38.3 & 25.2 \\
PL & 1.9 & 970.8 & 519.7 & 0.0 & 52.0 \\
PT & 20.8 & 544.0 & 26.3 & 2.0 & $2,274.7$ \\
SE & 59.9 & $21,819.8$ & 366.5 & 6.2 & 105.9 \\
US & $22,999.5$ & $33,468.1$ & 1.5 & 72.8 & 420.5 \\
Total & $1,579.5$ & $6,208.2$ & 68.6 & 27.7 & \\
\hline
\end{tabular}

$\dagger$ Weekly sales and weekly Spotify streams are in thousands units.

Table 3: US Weekly Sales Values (April 2013 - December 2014)

\begin{tabular}{lccccc}
\hline \hline \multicolumn{1}{c}{ Variable } & Mean & Std. Dev. & Min. & Max. & N \\
\hline Digital Tracks & 21732.51 & 2962.21 & 16882 & 36311 & 86 \\
Physical Albums & 4893.2 & 892.45 & 3971 & 9878 & 86 \\
Digital Albums & 2081.59 & 261.06 & 1694 & 3486 & 86 \\
Spotify Streams & 53544.25 & 20660.14 & 26108.42 & 108247.12 & 86 \\
\hline
\end{tabular}


Table 4: Song and Artist-level Displacement Estimates. ${ }^{\dagger}$

\begin{tabular}{lccccc}
\hline \hline & \multicolumn{5}{c}{ Dependent Variable: Sales } \\
\cline { 2 - 6 } & $\begin{array}{c}(1) \\
\text { Coef./s.e. }\end{array}$ & $\begin{array}{c}(2) \\
\text { Coef./s.e. }\end{array}$ & $\begin{array}{c}(3) \\
\text { Coef./s.e. }\end{array}$ & $\begin{array}{c}(4) \\
\text { Coef./s.e. }\end{array}$ & $\begin{array}{c}(5) \\
\text { Coef./s.e. }\end{array}$ \\
\hline Streams & $0.0707^{* * *}$ & $0.0694^{* * *}$ & $0.0700^{* * *}$ & $0.0697^{* * *}$ & $0.0714^{* * *}$ \\
& $(0.0005)$ & $(0.0007)$ & $(0.0007)$ & $(0.0008)$ & $(0.0009)$ \\
\hline & $\boldsymbol{x}$ & $\checkmark$ & $\checkmark$ & $\checkmark$ & $\checkmark$ \\
Country FE & $\boldsymbol{x}$ & $\boldsymbol{x}$ & $\checkmark$ & $\checkmark$ & - \\
Week FE & $\boldsymbol{x}$ & $\boldsymbol{x}$ & $\boldsymbol{x}$ & $\checkmark$ & - \\
Song FE & $\boldsymbol{x}$ & $\boldsymbol{x}$ & $\boldsymbol{x}$ & $\boldsymbol{x}$ & $\checkmark$ \\
Song-Week FE & & & & & \\
\hline & & & & & \\
$\mathrm{R}^{2}$ & & & & & \\
No. of Obs. & 24538 & 24538 & 24538 & 24538 & 24538 \\
& & & & & \\
\hline \hline
\end{tabular}

Dependent Variable: Piracy

$\begin{array}{llllll}(1) & (2) & (3) & \text { (4) }\end{array}$

Coef./s.e. Coef./s.e. Coef./s.e. Coef./s.e. Coef./s.e.

\begin{tabular}{lccccc}
\hline Streams & $0.0248^{* * *}$ & $0.0249^{* * *}$ & $0.0210^{* * *}$ & $0.0216^{* * *}$ & $0.0213^{* * *}$ \\
& $(0.0004)$ & $(0.0004)$ & $(0.0004)$ & $(0.0004)$ & $(0.0004)$ \\
\hline Country FE & $\boldsymbol{x}$ & $\boldsymbol{x}$ & $\checkmark$ & $\checkmark$ & $\checkmark$ \\
Week FE & $\boldsymbol{x}$ & $\checkmark$ & $\checkmark$ & $\checkmark$ & - \\
Artist FE & $\boldsymbol{x}$ & $\boldsymbol{x}$ & $\boldsymbol{x}$ & $\checkmark$ & - \\
Artist-Week FE & $\boldsymbol{x}$ & $\boldsymbol{x}$ & $\boldsymbol{x}$ & $\boldsymbol{x}$ & $\checkmark$ \\
\hline & & & & & \\
$\mathrm{R}^{2}$ & 0.175 & 0.190 & 0.255 & 0.403 & 0.550 \\
No. of Obs. & 21324 & 21324 & 21324 & 21324 & 21324 \\
\hline
\end{tabular}

$\dagger$ Standard errors are in parenthesis.

* Significant at the $10 \%$ level.

** Significant at the $5 \%$ level.

*** Significant at the $1 \%$ level. 
Table 5: Aggregate Sales Displacement Estimates. ${ }^{\dagger}$

\begin{tabular}{|c|c|c|c|c|c|}
\hline & \multicolumn{5}{|c|}{ Matched Aggregate Dataset } \\
\hline & $\begin{array}{c}\text { All } \\
(1) \\
\text { Coef./s.e. }\end{array}$ & $\begin{array}{c}\text { All } \\
(2) \\
\text { Coef./s.e. }\end{array}$ & $\begin{array}{c}\text { All } \\
(3) \\
\text { Coef./s.e. }\end{array}$ & $\begin{array}{c}\text { US only } \\
(4) \\
\text { Coef./s.e. }\end{array}$ & $\begin{array}{c}\text { US only } \\
(5) \\
\text { Coef./s.e. }\end{array}$ \\
\hline Streams & $\begin{array}{l}0.0770^{* * *} \\
(0.0020) \\
\end{array}$ & $\begin{array}{l}-0.0241^{* * *} \\
(0.0049) \\
\end{array}$ & $\begin{array}{l}-0.0234^{* * *} \\
(0.0054) \\
\end{array}$ & $\begin{array}{l}-0.0363 \\
(0.0264) \\
\end{array}$ & $\begin{array}{l}-0.0659^{*} \\
(0.0342) \\
\end{array}$ \\
\hline $\begin{array}{l}\text { Country FE } \\
\text { Week FE }\end{array}$ & $\begin{array}{l}x \\
x\end{array}$ & $\begin{array}{l}\checkmark \\
x\end{array}$ & $\begin{array}{l}\checkmark \\
\checkmark\end{array}$ & $\begin{array}{l}- \\
-\end{array}$ & Time trend \\
\hline \multirow[t]{3}{*}{ No. of Obs. } & $\begin{array}{c}0.682 \\
719\end{array}$ & $\begin{array}{c}0.945 \\
719\end{array}$ & $\begin{array}{c}0.948 \\
719\end{array}$ & $\begin{array}{c}0.053 \\
36\end{array}$ & $\begin{array}{c}0.102 \\
36\end{array}$ \\
\hline & \multicolumn{5}{|c|}{ Overall Aggregate Dataset } \\
\hline & $\begin{array}{c}\text { All } \\
(1) \\
\text { Coef./s.e. }\end{array}$ & $\begin{array}{c}\text { All } \\
(2) \\
\text { Coef./s.e. }\end{array}$ & $\begin{array}{c}\text { All } \\
(3) \\
\text { Coef./s.e. }\end{array}$ & $\begin{array}{l}\text { US only } \\
(4) \\
\text { Coef./s.e. }\end{array}$ & $\begin{array}{c}\text { US only } \\
(5) \\
\text { Coef./s.e. }\end{array}$ \\
\hline Streams & $\begin{array}{l}0.4533^{* * *} \\
(0.0151) \\
\end{array}$ & $\begin{array}{l}-0.2146^{* * *} \\
(0.0272) \\
\end{array}$ & $\begin{array}{l}-0.2293^{* * *} \\
(0.0293) \\
\end{array}$ & $\begin{array}{l}-0.3849^{* *} \\
(0.1577) \\
\end{array}$ & $\begin{array}{l}-0.4455^{* *} \\
(0.1994) \\
\end{array}$ \\
\hline $\begin{array}{l}\text { Normalized Coefficient } \\
\text { Reciprocal }\end{array}$ & $\begin{array}{l}.0405 \\
24.7\end{array}$ & $\begin{array}{l}-.0192 \\
-52.1\end{array}$ & $\begin{array}{l}-.0205 \\
-48.8\end{array}$ & $\begin{array}{l}-.0344 \\
-29.1\end{array}$ & $\begin{array}{l}-.0398 \\
-25.1\end{array}$ \\
\hline $\begin{array}{l}\text { Country FE } \\
\text { Week FE }\end{array}$ & $\begin{array}{l}x \\
x\end{array}$ & $\begin{array}{l}\checkmark \\
x\end{array}$ & $\begin{array}{l}\checkmark \\
\checkmark\end{array}$ & - & $\begin{array}{c}- \\
\text { Time trend }\end{array}$ \\
\hline $\begin{array}{l}\mathrm{R}^{2} \\
\text { No. of Obs. }\end{array}$ & $\begin{array}{c}0.556 \\
722\end{array}$ & $\begin{array}{c}0.972 \\
722\end{array}$ & $\begin{array}{c}0.974 \\
722\end{array}$ & $\begin{array}{c}0.149 \\
36\end{array}$ & $\begin{array}{c}0.156 \\
36\end{array}$ \\
\hline
\end{tabular}

$\dagger$ Standard errors are in parenthesis.

* Significant at the $10 \%$ level.

** Significant at the $5 \%$ level.

*** Significant at the $1 \%$ level. 
Table 6: Aggregate Piracy Displacement Estimates. ${ }^{\dagger}$

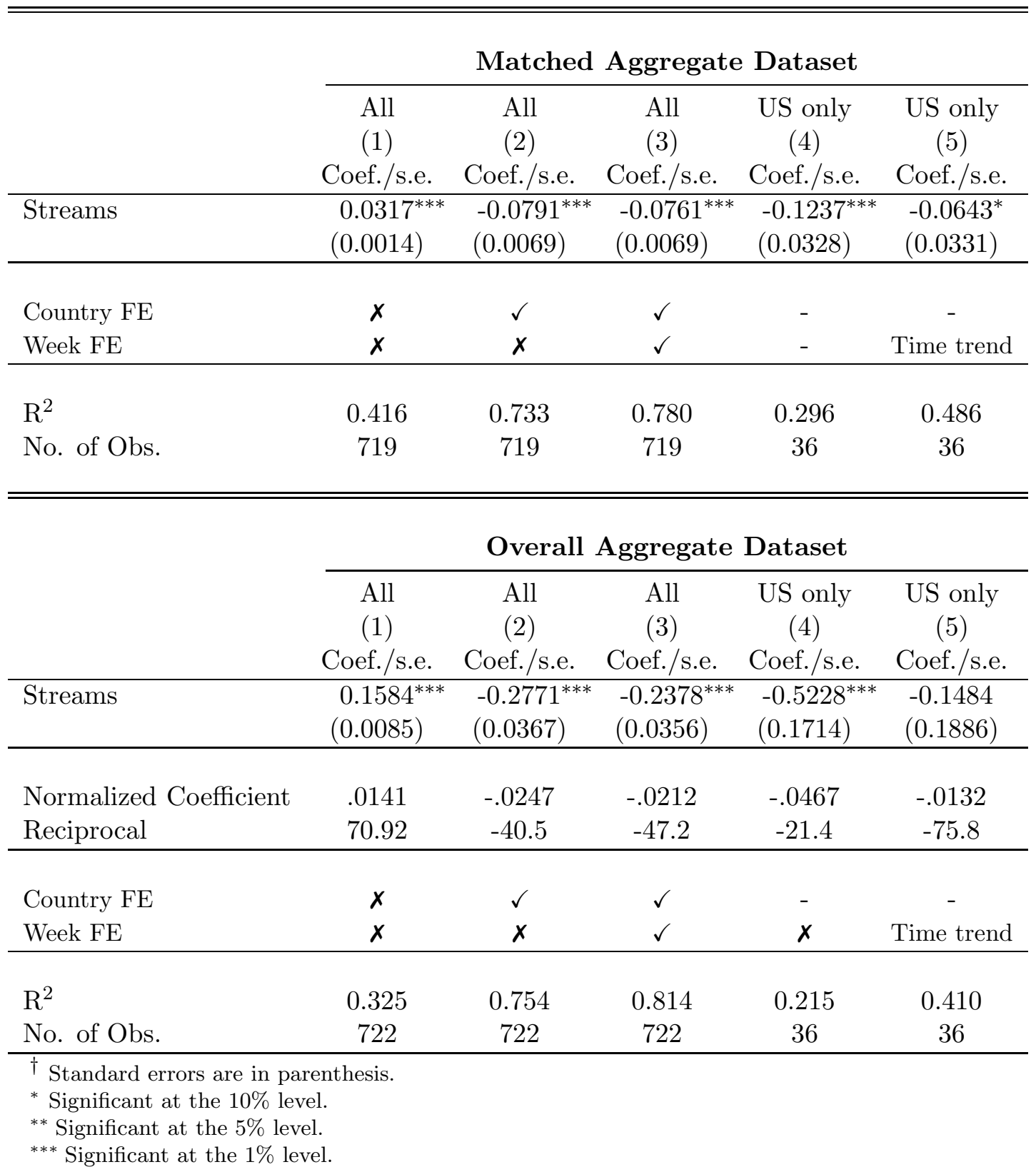


Table 7: Aggregate Sales Displacement Estimates, US Recorded Music Sales (April 2013-March 2015)..$^{\dagger}$

\begin{tabular}{|c|c|c|c|}
\hline & \multicolumn{3}{|c|}{ Dependent Variable: Sales } \\
\hline & $\begin{array}{c}\text { Digital Tracks } \\
(1) \\
\text { Coef./s.e. } \\
\end{array}$ & $\begin{array}{c}\text { Physical Albums } \\
(2) \\
\text { Coef./s.e. }\end{array}$ & $\begin{array}{c}\text { Digital Albums } \\
(3) \\
\text { Coef./s.e. } \\
\end{array}$ \\
\hline Streams & $\begin{array}{l}-0.0813^{* * *} \\
(0.0069)\end{array}$ & $\begin{array}{l}-0.0068^{* *} \\
(0.0032)\end{array}$ & $\begin{array}{l}-0.0020 \\
(0.0013) \\
\end{array}$ \\
\hline $\begin{array}{l}\text { Normalized Coefficient } \\
\text { Reciprocal }\end{array}$ & $\begin{array}{c}-.0073 \\
-137 \\
\end{array}$ & $\begin{array}{r}-.0006 \\
-1666.7 \\
\end{array}$ & $\begin{array}{l}-.0002 \\
-5000 \\
\end{array}$ \\
\hline \multirow[t]{3}{*}{ No. of Obs. } & $\begin{array}{c}0.941 \\
86\end{array}$ & $\begin{array}{c}0.864 \\
86\end{array}$ & $\begin{array}{l}0.719 \\
86\end{array}$ \\
\hline & \multicolumn{3}{|c|}{ Dependent Variable: $\log ($ Sales $)$} \\
\hline & $\begin{array}{c}\text { Digital Tracks } \\
(1) \\
\text { Coef./s.e. }\end{array}$ & $\begin{array}{c}\text { Physical Albums } \\
(2) \\
\text { Coef./s.e. }\end{array}$ & $\begin{array}{c}\text { Digital Albums } \\
(3) \\
\text { Coef./s.e. }\end{array}$ \\
\hline $\log ($ Streams $)$ & $\begin{array}{l}-0.2066^{* * *} \\
(0.0130) \\
\end{array}$ & $\begin{array}{l}-0.0989^{* * *} \\
(0.0320) \\
\end{array}$ & $\begin{array}{l}-0.0692^{* *} \\
(0.0320) \\
\end{array}$ \\
\hline $\mathrm{R}^{2}$ & 0.960 & 0.828 & 0.696 \\
\hline No. of Obs. & 86 & 86 & 86 \\
\hline \multicolumn{4}{|c|}{$\begin{array}{l}\dagger \text { Digital tracks are total sales of standalone digital tracks, as reported in Billboard. Weekly } \\
\text { US data for } 2013 \text {-early } 2015 \text {. Spotify streams are the sum of streams for the Top } 50 \text { songs, } \\
\text { according to Spotify charts. Standard errors are in parenthesis. All specifications include } \\
\text { week fixed effects. } \\
{ }^{*} \text { Significant at the } 10 \% \text { level. } \\
{ }^{* *} \text { Significant at the } 5 \% \text { level. } \\
\text { *** Significant at the } 1 \% \text { level. }\end{array}$} \\
\hline
\end{tabular}

